PEMBELAJAR: Jurnal Ilmu Pendidikan, Keguruan, dan Pembelajaran

Volume 4 Nomor 1 April 2020

e-ISSN: 2549-9114 dan p-ISSN: 2549-9203

(Received: Januari 2020; Reviewed: Maret 2020; Published: April 2020)

DOI : 10.26858/pembelajar.v4i1.12024

\title{
Efektivitas Experiential Learning Dalam Meningkatkan Pemahaman Materi Psikologi Perkembangan
}

\author{
Ince Prabu Setiawan Bakar \\ Program Studi Pendidikan Guru Sekolah Dasar \\ Universitas Islam Makassa
}

Corresponding e-mail: inceprabusetiawanbakar.dty@uim-makassar

\begin{abstract}
Abstrak: Efektivitas Experiential Learning dalam Meningkatkan Pemahaman Materi Psikologi Perkembangan. Tujuan penelitian bertujuan mengetahui peningkatan active learning mahasiswa pada mata kuliah psikologi perkembangan dengan metode experiential learning theory dan untuk mengetahui peningkatan hasil belajar mahasiswa pada mata kuliah psikologi perkembangan dengan metode experiential learning theory. Penelitian ini menggunakan metode ekperimen. Metode pembelajaran yang dilakukan dalam eksperimen ini menggunakan model pembelajaran experiential learning. Hipotesis dalam penelitian ini adalah pemahaman materi psikologi perkembangan mahasiswa PGSD yang diajar dengan metode experiential learning lebih tinggi dibandingkan kelompok yang tidak menggunakan metode experiential learning. Sampel pada penelitian ini adalah mahasiswa PGSD yang sedang mengambil mata kuliah psikologi perkembangan. Untuk menguji hasilnya digunakan hasil uji-t. Hasil penelitian menunjukkan Penggunaan model pembelajaran eksperiential learning berpengaruh terhadap hasil belajar siswa di PGSD berdasarkan nilai Sig. (2-tailed) $<0,05$, diketahui bahwa ada perbedaan yang signifikan antara hasil belajar kelas eksperimen dan kelas kontrol.
\end{abstract}

Kata kunci: experiential learning, psikologi perkembangan.

Abstract: Effectiveness of Experiential Learning in Improving Understanding of Developmental Psychology Materials. The purpose of this research is to find out the improvement of students' active learning in developmental psychology subjects with experiential learning theory methods and to find out the increase in student learning outcomes in developmental psychology subjects with experiential learning theory methods. This research uses an experimental method. The learning method carried out in this experiment uses the experiential learning model. The hypothesis in this study is the understanding of the psychology of PGSD students' developmental material taught by experiential learning method is higher than the group that does not use experiential learning method. The sample in this study were PGSD students who were taking developmental psychology courses. To test the results used t-test results. The results showed the use of experiential learning learning models affect student learning outcomes in PGSD based on Sig. (2-tailed) <0.05, it is known that there is a significant difference between the learning outcomes of the experimental class and the control class.

Keywords: experiential learning, developmental psychology. 


\section{PENDAHULUAN}

Mata kuliah psikologi perkembangan merupakan salah satu matakuliah wajib pada Program Studi Pendidikan Guru Sekolah Dasar (PGSD) Sasaran pemberlajaran dari mata kuliah ini adalah mahasiswa diharapkan memahami perkembangan mulai dari tahap neonatal hingga usia lanjut serta karakteristik tiap tahap perkembangan. Mata kuliah ini akan menunjang pemahaman mahasiswa terhadap individu khususnya peserta didik di sekolah dasar. Tidak hanya itu, dengan kemampuan mereka memahami karakteristik dan tugas perkembangan peserta didik, mahasiswa menjadi mampu menyesuaikan metode pembelajarannya dengan karakteristik peserta didik yang dihadapinya.

Proses pembelajaran yang telah diterapkan selama ini pada umumnya menggunakan metode ceramah interaktif dimana dosen akan menjelaskan materi perkuliahan dan memberikan kesempatan kepada mahasiswa bertanya di akhir sesi. Selain itu, beberapa dosen juga menggunakan metode diskusi dimana mahasiswa akan mempresentasikan materi sesuai dengan topik yang telah dibagikan ke tiap kelompok yang kemudian diakhiri dengan sesi tanya jawab. Pada dasarnya kedua metode yang diterapkan cukup interaktif, artinya telah terjadi hubungan timbal balik antara dosen dan mahasiswa dalam proses pembelajaran. Hanya sajam metode ini dinilai membosankan oleh mahasiswa dikarenakan hampir pada semua mata kuliah pun menggunakan metode pembelajaran yang sama. Sehingga mahasiswa peserta mata kuliah tidak termotivasi dan menjadi lebih pasif, yang membuat pemahaman mahasiswa terkait materi rendah. Hanya sebagian mahasiswa yang betul-betul melibatakan diri dalam perkuliahan, sementara yang lainnya akan cenderung pasif.

Selain itu, dalam evaluasi perkulihan, mahasiswa cenderung hanya akan menghapal materi perkuliahan ketika ujian. Metode tersebut juga membuat mahasiswa kurang mampu mengeksplorasi kemampuan dirinya dalam memperluas wawasannya terkait materi yang sedang di dalami. Oleh sebab itu, diperlukan metode-metode pembelajaran yang lebih interaktif agar mahasiswa termotivasi untuk dapat memahami materi dalam mata kuliah psikologi perkembangan. Oleh karena itu, agar tebangun iklim active learning dalam proses pembelajaran di kelas, maka kami ajukan Experiential Learning Theory sebagai pembaharuan metode pembelajaran di kelas.
Diharapkan active learning akan dapat berjalan melalui gabungan beberapa metode perkuliahan assignment submittance, jigsaw, roleplay, dan think-pair-shared (analisis kasus, diskusi kelompok kecil, presentasi [gallery walk], yang diakhiri diskusi kelompok besar). Beberapa penelitian membuktikan bahwa metode experiential learning ini cukup efektif dalam peningkatan pemahaman dan nilai ratarata peserta didik pada materi-materi tertentu (Hariri, Citra Apriovilita, dkk, 2017; Kusmiati 2017).

Experiential Learning Theory yang melibatkan belajar dengan memikirkan, merencanakan, merasakan, mengamati, mencerminkan dan melakukan ini perlu diimplementasikan ke mata kuliah ini karena cakupan teori yang luas dan butuh visualisasi teori untuk memahami lebih dalam materimateri yang ada. Implementasi metode ini diharapkan mahasiswa memiliki pemahaman filosofis tentang paradigma penelitian kualitatif, memberikan pengetahuan dan keterampilan dalam proses penelitian kualitatif agar mahasiswa mampu menggunakannya dalam penelitian bidang psikologi. Berdasarkan rumusan masalah tersebut maka tujuan yang ingin dicapai adalah untuk mengetahui peningkatan active learning mahasiswa pada mata kuliah psikologi perkembangan dengan metode Experiential Learning Theory dan Untuk mengetahui peningkatan hasil belajar mahasiswa pada mata kuliah psikologi perkembangan dengan metode Experiential Learning Theory. Adapun manfaat penelitian ini adalah diharapkan mahasiswa bisa berperan aktif dalam proses belajar sehingga lebih baik dalam pemahaman terkait topik/materi, juga kreatif serta aktif pada penggunaan multimedia pembelajaran.

\section{METODE}

Jenis penelitian yang digunakan dalam penelitian ini adalah penelitian kuantitatif eksperimental. Desain penelitian yang digunakan adalah eksperimen kuasi dengan desain eksperimen yaitu nonrandomized pretest-posttest control group design. Nonrandomized pretest-posttest control group design merupakan desain eksperimen yang membentuk kelompok eksperimen yang diberikan perlakukan dan kelompok control yang tidak mendapatkan perlakuan. Selain itu, pada desain penelitian ini dilakukan proses pemberian pretest yang dilakukan sebelum perlakuan dan pemberian posttest yang 
dilakukan pasca adanya perlakuan. Pada desain penelitian ini pula, keefektifan atau pengaruh variabel independen terhadap variabel dependen dapat dilihat dari perbedaan hasil pretest dengan posttest.

Sampel pada penelitian ini adalah mahasiswa PGSD yang sedang mengambil mata kuliah psikologi perkembangan. Sebagai kontrol dalam penelitian ini adalah melakukan radom terhadap kelas A dan B untuk menentukan kelompok eksperiemen dan kelompok kontrol. Kelompok ekperimen akan diberikan metode ekperiential learning, sementara kelompok kontrol tidak diberikan perlakuan. Untuk menguji hasilnya digunakan hasil uji-t. Penelitian ini dilakukan melalui beberapa tahapan dimulai dari penyusunan proposal, persiapan eksperimen, eksperiment, analisis data, dan penyusunan laporan akhir penelitian.

\section{HASIL DAN PEMBAHASAN}

Deskripsi Data Hasil Belajar Siswa Kelas Eksperimen dan Kontrol

Berdasarkan tabel 1 dapat dilihat bahwa mean atau rata-rata nilai hasil belajara pretest siswa 31,42 dari skor ideal 100 yang mungkin dicapai oleh siswa berada pada kategori kurang. Standar deviasinya yaitu 8,64 hasil ini menunjukkan distribusi hasil belajar pretest pada kelompok eksperimen tersebar dari skor minimum 20 sampai dengan skor maksimun 50 dengan median 30 .

Tabel 1. Frekuensi Pretest Kelas Eksperimen

\begin{tabular}{cc}
$\mathbf{N}$ & 14 \\
\hline Mean & 31,428 \\
\hline Median & 30 \\
\hline Std. Deviation & 8,64 \\
\hline Min. & 20 \\
\hline Max. & 50 \\
\hline Jumlah & 440
\end{tabular}

Sumber: Hasil olahan kuesioner 2019

\begin{tabular}{cccc}
\hline Nilai & Frequency & $\begin{array}{c}\text { Valid } \\
\text { Percent }\end{array}$ & $\begin{array}{c}\text { Cumulative } \\
\text { Percent }\end{array}$ \\
\hline $\mathbf{2 0}$ & 3 & 21,4 & 21.4 \\
\hline $\mathbf{3 0}$ & 7 & 50,0 & 71,4 \\
\hline $\mathbf{4 0}$ & 3 & 21,4 & 92,9 \\
\hline
\end{tabular}

\begin{tabular}{rccc}
\hline $\mathbf{5 0}$ & 1 & 7,1 & 100,0 \\
Jumlah & 14 & 100,0 & \\
\hline
\end{tabular}

Sumber: IBM SPSS Statistics version 20

Tabel 1 menunjukkan hasil pretest di kelas eksperimen. 3 siswa yang mendapat nilai 20 dengan persentase $21,4 \%, 7$ siswa yang mendapat nilai 30 dengan persentase $750 \%, 3$ siswa yang mendapat nilai 40 dengan persentase $21,4 \%, 1$ siswa yang mendapat nilai 50 dengan persentase $7,1 \%$.

Tabel 2. Frekuensi Pretest Kelas Kontrol

\begin{tabular}{cc}
\hline $\mathbf{N}$ & 14 \\
\hline Mean & 30,71 \\
\hline Median & 30 \\
\hline Std. Deviation & 9,97 \\
\hline Min. & 20 \\
\hline Max. & 50 \\
\hline Jumlah & 430 \\
\hline
\end{tabular}

Sumber: Hasil olahan kuesioner

2019

\begin{tabular}{cccc}
\hline Nilai & Frequency & $\begin{array}{c}\text { Valid } \\
\text { Percent }\end{array}$ & $\begin{array}{c}\text { Cumulative } \\
\text { Percent }\end{array}$ \\
\hline $\mathbf{2 0}$ & 5 & 35,7 & 35,7 \\
\hline $\mathbf{3 0}$ & 4 & 28,6 & 64,3 \\
\hline $\mathbf{4 0}$ & 4 & 28,6 & 92,9 \\
\hline $\mathbf{5 0}$ & 1 & 7,1 & 100,0 \\
Jumlah & 14 & 100,0 & \\
\hline Sumber: IBM SPSS Statistics version 20
\end{tabular}

Sumber: IBM SPSS Statistics version 20

Tabel tersebut menunjukkan hasil pretest di kelas kontrol. 3 siswa yang mendapat nilai 25 dengan persentase $21,4 \%, 2$ siswa yang mendapat nilai 30 dengan persentase $14,3 \%, 2$ siswa yang mendapat nilai 35 dengan persentase $14,3 \%, 3$ siswa yang mendapat nilai 40 dengan persentase $21,4 \%$, 1 siswa yang mendapat nilai 50 dengan persentase $7,1 \%$. 
Tabel 3. Perbandingan Data Pre-Test Kelas Eksperimen dan Kelas Kontrol

\begin{tabular}{clcc}
\hline No & Statistik & \multicolumn{2}{c}{ Kelas } \\
\cline { 3 - 4 } & & Eksperimen & Kontrol \\
\hline $\mathbf{1}$ & $\mathrm{N}$ & 14 & 14 \\
\hline $\mathbf{2}$ & Mean & 31,43 & 30,71 \\
\hline $\mathbf{3}$ & Std. Deviation & 8,64 & 9,97 \\
\hline
\end{tabular}

Sumber: IBM SPSS Statistics version 20

Berdasarkan tabel 3 dapat dilihat bahwa mean atau rata-rata nilai hasil belajar pretest mahasiswa kelompok eksperimen adalah 31,43 dari skor ideal 100 yang mungkin dicapai oleh siswa berada pada kategori kurang dengan standar deviasi 8,64.

Deskripsi Data Postest Setelah diterapkan model pembelajaran experiential learning dengan jigsaw pada kelompok eksperimen maka disajikan data posttest hasil belajar mahasiswa kelompok kontrol dan eksperimen untuk membandingkan dengan data pretest yang diperoleh sebelum penerapan model pembelajaran.

Berdasarkan tabel 4 dapat dilihat bahwa mean atau rata-rata nilai hasil belajara pretest mahasiswa kelas eksperiam 67,14 dari skor ideal 100 yang mungkin dicapai oleh siswa berada pada kategori kurang. Standar deviasinya yaitu 13,83. Tabel 4 Frekwensi Data Postest Kelas

Eksperimen

\begin{tabular}{cc}
\hline $\mathbf{N}$ & 14 \\
\hline Mean & 67,1429 \\
\hline Median & 70 \\
\hline Std. Deviation & 13,83 \\
\hline Min. & 40 \\
\hline Max. & 90 \\
\hline Jumlah & 940
\end{tabular}

Sumber: IBM SPSS Statistics version 20

\begin{tabular}{cccc}
\hline Nilai & Frequency & $\begin{array}{c}\text { Valid } \\
\text { Percent }\end{array}$ & $\begin{array}{c}\text { Cumulative } \\
\text { Percent }\end{array}$ \\
\hline $\mathbf{4 0}$ & 1 & 7,1 & 7,1 \\
\hline $\mathbf{5 0}$ & 2 & 14,3 & 21,4 \\
\hline $\mathbf{6 0}$ & 2 & 14,3 & 35,7 \\
\hline $\mathbf{7 0}$ & 5 & 35,7 & 71,4 \\
\hline $\mathbf{8 0}$ & 3 & 21,4 & 92,9 \\
\hline $\mathbf{9 0}$ & 1 & 7,1 & 100 \\
\hline Jumlah & 14 & 100,0 & \\
\hline
\end{tabular}

Tabel diatas menunjukkan hasil postest di kelas eksperimen. 1 siswa yang mendapat nilai 40 dengan persentase $7,1 \%, 2$ siswa yang mendapat nilai 50 dengan persentase 14,3\%, 2 siswa yang mendapat nilai 60 dengan persentase $14,3 \%, 5$ siswa yang mendapat nilai 70 dengan persentase $35,7 \%$, 3 Siswa mendapat nilai 80 dengan persentase $21,4 \%$ dan 1 siswa mendapat nilai 90 dengan persentasi $7,1 \%$.

Selanjutnya berdasarkan tabel 5 dapat dilihat bahwa mean atau rata-rata nilai hasil belajara pretest mahasiswa kelas Kontrol 42,85 dari skor ideal 100 yang mungkin dicapai oleh siswa berada pada kategori kurang. Standar deviasinya yaitu 9,14.

Tabel 5 Frekwensi Data Postest Kelas Kontrol

\begin{tabular}{cc}
\hline $\mathbf{N}$ & 14 \\
\hline Mean & 42,85 \\
\hline Median & 40 \\
\hline Std. Deviation & 9,14 \\
\hline Min. & 30 \\
\hline Max. & 60 \\
\hline Jumlah & 600
\end{tabular}

Sumber: IBM SPSS Statistics version 20

\begin{tabular}{cccc}
\hline Nilai & Frequency & $\begin{array}{c}\text { Valid } \\
\text { Percent }\end{array}$ & $\begin{array}{c}\text { Cumulative } \\
\text { Percent }\end{array}$ \\
\hline $\mathbf{3 0}$ & 2 & 14,3 & 14,3 \\
\hline $\mathbf{4 0}$ & 8 & 57,1 & 71,4 \\
\hline $\mathbf{5 0}$ & 2 & 14,3 & 85,7 \\
\hline $\mathbf{6 0}$ & 2 & 14,3 & 100,0 \\
\hline Jumlah & 14 & 100,0 & \\
\hline
\end{tabular}

Sumber: IBM SPSS Statistics version 20

Tabel diatas menunjukkan hasil postest di kelas kontrol. 2 siswa yang mendapat nilai 30 dengan persentase $14,3 \%, 8$ siswa yang mendapat nilai 40 dengan persentase 57,1, 2 siswa yang mendapat nilai 50 dengan persentase $14,3 \%, 2$ siswa yang mendapat nilai 60 dengan persentase $14,3 \%$. 
Tabel 6. Perbandingan Data Post-Test Kelas Eksperimen dan Kelas Kontrol

\begin{tabular}{clcc}
\hline No & Statistik & \multicolumn{2}{c}{ Kelas } \\
\cline { 3 - 4 } & & Eksperimen & Kontrol \\
\hline $\mathbf{1}$ & $\mathrm{N}$ & 31,43 & 14 \\
\hline $\mathbf{2}$ & Mean & 8,64 & 9,97 \\
\hline $\mathbf{3}$ & Std. Deviation & \\
\hline
\end{tabular}

Sumber: IBM SPSS Statistics version 20

Berdasarkan tabel diatas dapat dilihat bahwa mean atau rata-rata nilai hasil belajara posttest mahasiswa 67,14 dari skor ideal 100 yang mungkin dicapai oleh siswa berada pada kategori baik. Standar deviasi13,85, hasil ini menunjukkan distribusi hasil belajar postest pada kelas eksperimen tersebar dari skor minimum 40 sampai dengan skor maksimun 90. Sementara itu, mean atau rata-rata nilai hasil belajara postest mahasiswa kelas kontrol 42,85 dari skor ideal 100 yang mungkin dicapai oleh mahasiswa berada pada kategori baik. Standar deviasi 9,14, hasil ini menunjukkan distribusi hasil belajar postest pada kelompok eksperimen tersebar dari skor minimum 30 sampai dengan skor maksimun 60.

Uji hipotesis yang dulakukan dapat diketahui Independent Sample T-Test digunakan untuk menguji dua sampel data yang tidak saling berhubungan. Analisis ini dilakukan dengan meguji hasil pretest kelas ekperimen dan pretest kelas kontrol dengan menggunakan sistem

Statistical Pachage for Sosial Science (SPSS) versi 20.0. Syarat data dikatakan signifikan apabila nilai Sig. (2-tailed)< 0,05. Analisis ini bertujuan untuk mengetahui perbedaan hasil belajar antara kelas eksperimen dan kelas kontrol sebelum diberikan perlakuan. Berikut ini adalah hasil

IndependentSample T-Test nilai pre-test kelas eksperimen dan kelas kontrol.

Tabel 7 Hasil Independent Sample T-Test nilai pretest kelas eksperimen dan kelas kontrol

\begin{tabular}{lcccc}
\hline \multicolumn{1}{c}{ Data } & & N & Df & Sig.(2tailed) \\
$\begin{array}{l}\text { G-Gain } \\
\text { Persentil }\end{array}$ & Eksperimen & 14 & 53,16 & 17,31 \\
& Kontrol & 14 & 16,59 & 14,79 \\
\hline
\end{tabular}

\begin{tabular}{|l|c|c|c|c|c|c|}
\hline \multicolumn{7}{|c|}{ T-test } \\
\hline Data & & F & Sig & t & df & $\begin{array}{l}\text { Sig. } \\
\mathbf{2} \\
\text { taild } \\
\mathbf{~}\end{array}$ \\
\hline $\begin{array}{l}\text { G-Gain } \\
\begin{array}{l}\text { Persent } \\
\text { il }\end{array}\end{array}$ & $\begin{array}{c}\text { Eksperi } \\
\text { men }\end{array}$ & 7,40 & 0,39 & 6,0 & 26 & 0,00 \\
\hline & Kontrol & & & 08 & & 0 \\
\hline
\end{tabular}

Sumber: IBM SPSS Statistics version 20

Tabel tujuh menunjukkan perbedaan score ditinjau dari gaint score kelompok eksperimen dan kelompok kontrol. Baik kelompok eksperimen maupun kelompok kontrol menunjukkan adanya perbedaan skor $>0,05$, yang artinya ada perbedaan yang signifikan hasil belajar antara kelompok yang menggunakan Model pembelajaran experiential learning:jigsaw dengan kelompok yang tidak menggunakan Model pembelajaran kooperatif tipe experiential learning. Berdasarkan hasil data tersebut, dapat disimpulkan hasil uji hipotesis sebagai berikut:

$\mathrm{H}_{0}=$ Tidak ada pengaruh model pembelajaran experiential learning:jigsaw terhadap hasil belajar mahasiswa pada mata kuliah psikologi perkembangan di PGSD FKIP UIM Makassar (Ditolak

karena Sig. $(2$-tailed $)<0,05)$

$\mathrm{H}_{\mathrm{a}}=$ Ada pengaruh model pembelajaran experiential learning:jigsaw terhadap hasil belajar mahasiswa pada mata kuliah psikologi perkembangan di PGSD FKIP UIM Makassar

(Diterima karena Sig. (2-tailed) $<0,05$ )

Penelitian ini menelaah tentang pengaruh penggunaan model pembelajaran eksperiential learning terhadap hasil belajar mahasiswa pada mata kuliah psikologi perkembangan. Penelitian dilaksanakan pada bulan oktober dengan standar kompetensi, kompetensi dasar serta materi yang sama antara kelas eksperimen dengan kelas kontrol. Penelitian ini menggunakan desain Quasi Eksperimental bentuk Non Equivalent control grup desaign.

Desain penelitian ini dipilih karena penelitian akan memberikan treatment berupa penggunaan model pembelajaran kooperatif experiential learning: jigsaw pada kelas eksperimen dan pada kelas kontrol tanpa menggunakan model pembelajaran ekperiential learning. Sampel dalam penelitian ini terdiri dari 28 orang mahasiswa yaitu kelas eksperimen sebanyak 14 orang dan kelas kontrol sebanyak 
14 orang. Teknik pengambilan sampel menggunakan teknik purposive sampling yaitu dengan pertimbangan hasil pretest mahasiswa. Sebelum penentuan yang termasuk dalam kelas eksperimen dan kelas kontrol terlebih dahulu diberikan pretest untuk mengetahui kemampuan awal mahasiswa. Setelah itu, diberikan treatment kemudian diberikan posttest membandingkan hasil belajar sebelum dan sesudah diberikan treatment.

Berdasarkan penelitian yang di lakukan menyatakan bahwa pembelajaran yang menggunakan model experiential learning: jigsaw berpengaruh terhadap hasil belajar siswa pada mata kuliah Psikologi perkembangan, setelah diadakan penelitian ditemukan perbedaan bahwa hasil belajar mahasiswa yang diajar menggunakan model pembelajaran eksperiential learning lebih baik dibandingkan dengan hasil belajar mahasiswa tanpa menggunakan model experiential learning: jigsaw. experiential learning: jigsaw adalah model pembelajaran dimana mahasiswa secara berkelompok berdiskusi terkait materi yang diberikan berdasarkan materi yang sudah disiapkan. Setiap kelompok mengkaji tema yang berbeda. Terdapat kelompok yang mengkaji mengenai pertumbuhan dan kelompok yang mengkaji terkait perkembangan. Selanjutnya setelah mereka yankin telah memahami dan menguasi tema yang menjadi bagian dari kelompok mereka, mahasiswa akan dibagi kembali kedalam kelompok yang lebih kecil dimana dalam kelompok tersebut terdiri dari kelompok pertumbuhan dan perkembangan. Di dalam kelompok mahasiswa saling bertukar materi yang telah mereka diskusikan sebelumnya dikelempok asal selanjutnya membuat summerize yang dituangkan dalam flip chart/karton yang telah disiapkan dengan cara yang mereka sepakati. Mereka boleh mengggunakan gambar, kata-kata sesuai kreatifitas mereka. Selanjutnya mereka mempresentasikan hasil posternya di depan kelas. Dosen akan memberi feedback jika ada perjelasan yang salah atau belum terjelaskan oleh kelompok. Sesi ini ditutup dengan penyampaian refleksi pengalaman mahasiswa.

Dengan metode tersebut, mahasiswa akan terlibat aktif dalam memahami materi serta menjelaskan kepada orang lain secara jelas dan sistematis. Mereka juga akan berupaya untuk memahami materi lebih mendalam agar mampu menjawab pertanyaan dari peserta mata kuliah lainnya. Pembelajaran kolaboratif yang berpusat pada mahasiswa sebagai subjek dinilai memberikan manfaat pada pemahaman mahasiswa yang lebih mendalam dan melekat terkait materi yang diberikan (Hariri, Citra Apriovilita, dkk,
2017; Kusmiati 2017)

Teori belajar experiential Kolb adalah salah satu teori pendidikan yang paling popular dan paling sering dikutip. Teori ini memegang peran penting dalam perumusan modernisasi pendidikan. Teori Experiential Learning melibatkan belajar dalam empat fase yang berhubungan dengan melakukan, merasakan, mengamati, mencerinkan, memikirkan dan merencanakan. Karakteristik penting dari teori ini adalah bahwa fase yang berbeda dihubungkan dengan gaya belajar tertentu. Orang berbeda dalam gaya belajar mereka. Kesadaran akan hal ini merupakan premis penting yang memungkinkan mahasiswa untuk menyadari kemungkinan, pendekatan alternative dan menjadi lebih fleksibel dalam situasi belajar yang berbeda. Dosen juga perlu menyadari gaya belajar mereka sendiri sebagai dasar pengembangan strategi pengajaran dan pembelajaran yang efektif. Sebuah permasalahan jika ada perbedaan antara gaya belajar mahasiswa dan apa yang diterapkan oleh dosen (Sharlanova, 2004).

Teori pembelajaran eksperiensial (ELT) telah digunakan secara luas dalam penelitian dan praktik manajemen pembelajaran selama lebih dari tiga puluh lima tahun. Sejalan dengan karya-karya mendasar Kurt Lewin, John Dewey dan lain-lain, teori pembelajaran eksperiensial menawarkan teori dinamis berdasarkan siklus belajar yang didorong oleh resolusi dialektika ganda tindakan/refleksi dan pengalaman/abstraksi. Kedua dimensi ini mendefinisikan ruang belajar holistic dimana belajar melakukan transaksi di antara individu dan lingkungan. Ruang belajar bersifat multi level dan dapat menggambarkan pembelajaran dan pengembangan secara sepadan pada tingkat individu, kelompok, dan organisasi.

\section{KESEIMPULAN}

Pendekatan ini diilustrasikan dengan meninjau penelitian terkini tentang gaya belajar individu dan pemecahan masalah manajerial/pengambilan keputusan, proses pembelajaran tim dan pembelajaran organisasi. penggunaan model eksperiential learning terhadap hasil belajar mahasiswa PGSD UIM, dilihat dari hasil lembar evaluasi mata kuliah psikologi perkembangan dapat dikatakan baik. Hal ini dilihat dari keaktifan siswa saat proses pembelajaran dan juga dilihat dari keterlaksanaan aspek yang diamati dilembar 
observasi pembelajaran dengan menggunakan model pembelajaran. Penggunaan model pembelajaran eksperiential learning berpengaruh terhadap hasil belajar siswa di PGSD berdasarkan nilai Sig. (2tailed) $<0,05$, diketahui bahwa ada perbedaan yang signifikan antara hasil belajar kelas eksperimen dan kelas kontrol.

\section{DAFTAR PUSTAKA}

Arum, \& Wahyu, S. A. 2007. Manajemen Arikunto, S. 2002. Prosedur Penelitian Suatu Pendekatan Praktek. Jakarta: PT. Rineka Cipta.

Azwar, S. 2010. Metode Penelitian. Yogyakarta: Pustaka Pelajar

Hariri, Citra Apriovilita\& Yayuk, Erna, 2017.

Penerapan Model Experiential Learning untuk Meningkatkan Pemahaman Materi Cahaya dan Sifat-Sifatnya Siswa Kelas 5 SD. PGSD FKIP Universitas Muhammadiyah

Malang

Kolb A.Y. \& Kolb D.A. 2008. Experiental LearningTheory: A Dynamic, Holistic Approach to Management Learning, Education and Development. Armstrong, S.J. \& Fukami, C. (Eds.) Handbook of Management Learning, Education and Development. London: Sage Publications

Kusmianti, 2017. Pengaruh Model Pembelajaran Eksperiential Learning terhadap konsep diri dan Pemahaman Konsep Fisika Siswa SMU. Gane Swara, vol. 11, No. 2, pp 100-110. Sharlanova V. 2004. Experiential Learning. Trakia Journal of Sciences, Vol. 2, No. 4, pp 36-39. Lumpkin Angela, R. M. 2014. student perception of active learning. college student hournal, 121-133.

Winterbottom, D. M. 2017. cambridge assesment international education. Retrieved from www.cambridgeinternational.org:http:// www.cambridgeinternational.org/image s/271174-active learning.pdf . 